\title{
DEPOIMENTO: ARQUITETA MIRANDA MAGNOLI
}

Entrevistadores:

Prof. Dr. Silvio Soares Macedo

Arquiteta Fany Galender

Transcrição:

Demétrius Borges dos S. G. de Araujo

Edição do depoimento:

Arquiteta Fany Galender

Arquiteta Ms. Solange Moura Lima Aragão

Demétrius Borges dos S. G. de Araujo

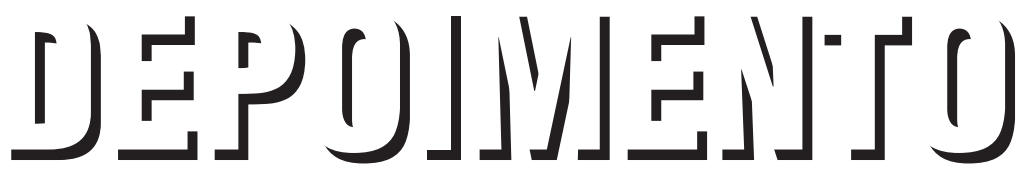




\title{
RESUMO
}

O Projeto QUAPÁ - do Laboratório da Paisagem da Faculdade de Arquitetura e Urbanismo da Universidade de São Paulo, apresenta uma entrevista da série "Ciclo de Depoimentos", concedida pela arquiteta Miranda Magnoli.

Neste contundente depoimento, a professora doutora, formada pela FAUUSP em 1955, fala sobre sua formação e seu decisivo e pioneiro papel na consolidação do ensino de paisagismo na universidade brasileira e, sobretudo, na implantação da pós-graduação voltada para as questões da paisagem e ambiente.

Atualmente, mantém atividade projetual, iniciada nos anos de 1950, com orientação de inúmeros pós-graduandos e a participação em eventos acadêmicos.

O texto que se segue é resultado da edição do material de gravação realizado no auditório da FAUUSP, no dia 16 de dezembro de 2003.

\begin{abstract}
The landscape architecture research group from the Faculdade de Arquitetura e Urbanismo da Universidade de São Paulo - QUAPÁ, continuing the series of interviews realized with contemporary landscapes architets from Brazil made this one with the architect Miranda Magnoloi, who was graduated in FAUUSP, in 1955.

It focuses on Magnoli's work as Ph.D. at FAUUSP, her formation as an architect and her decisive action in the consolidation of landscape architecture studies in the brazilian universities, especially on the creation of landscape and environment planning post-graduation studies.
\end{abstract}

The interview took place in FAUUSP's auditorium, São Paulo, on december $16^{\text {th }}$, 2003. 


\section{DEPOIMENTO: \\ ARQUITETA MIRANDA MAGNOLI}

\section{Formação e os Primeiros Tempos na FAUUSP}

Sou arquiteta e trabalho, quase exclusivamente, em atividades relacionadas à paisagem. É por meio da formação de arquiteta que trabalho em paisagismo. Toda minha atividade profissional foi pautada por uma concepção abrangente de arquitetura; esse entendimento inclui a área de Paisagem e explica sua implantação na FAU em 1948'.

Tive algumas experiências em campos diversos da arquitetura que foram muito benéficas para mim. Edificações, urbanismo, paisagismo, planos, projetos, obras em escritórios particulares, no escritório próprio, em órgãos públicos e anos de ensino em mais de uma área foram minhas atividades de trabalho. $\mathrm{Na}$ Faculdade de Arquitetura e Urbanismo da Universidade de São Paulo (FAUUSP), entrei na área de Projeto de Edificações, com o Abelardo de Souza, e fiquei uns bons anos, uns nove e, depois, tive a oportunidade de dar algum apoio a disciplinas de Planejamento Urbano. Em seguida - 1971/1972 - passei para a disciplina de Paisagismo - quando ainda estava sendo ministrada pelo (Antonio Augusto Azevedo) Antunes².

Na USP, na década de 1970, o doutoramento se tornou obrigatório para todos os quais não haviam defendido algum título na Universidade e, naquela

(1) "Meu conceito de arquitetura está na união e colaboração das artes em uma concepção ampla que abraça todo ambiente da vida humana; não podemos subtrair-nos à arquitetura, uma vez que fazemos parte da civilização, pois ela representa o conjunto das modificações e alterações introduzidas sobre a superfície da Terra face às necessidades humanas. Nem podemos confiar nossos interesses a uma elite de homens preparados (...) Cabe a cada um de nós se empenhar para a justa ordenação da paisagem terrestre, cada um com seu espírito e suas mãos, na parte que the cabe, evitando legar a nossos filhos um tesouro menor que aquele que nos foi deixado por nossos pais." Uma multiplicidade de formas e níveis de intervenção se legitimam com essa definição enunciada por William Morris, em 1881, ainda no início do movimento para a nova arquitetura.

(2) A "cadeira" de Arquitetura Paisagística inicia o lecionamento em 1952, no quinto ano, por Roberto Coelho Cardozo; contou com a participação da arquiteta Daisy lgel Honnenberg de 1953 a 1957; dos arquitetos Rodolpho Almeida Fernandes de 1957 a 1967; Antonio Augusto Azevedo Antunes de 1962 a 1974 ; de 1969-1970 o arquiteto Marcos Souza Dias deu seu apoio à disciplina; em 1971-1972 nós colaboramos com o Antunes. 
ocasião, era para ser realizado em um prazo curtíssimo, com duas disciplinas a serem cursadas. Quem faz a pós-graduação agora não tem a menor idéia do que foi a pós-graduação dessas situações pioneiras; tivemos, em dois meses, duas disciplinas gerais para toda e qualquer área. A própria orientação, como diz o Júlio Katinsky, "nós nem sabíamos o que era isso!". Tive como orientador o professor Nestor (Goulart Reis Filho), que considero um "super" pesquisador. Mas, naquela ocasião, ele tinha uma atividade extremamente importante em um período conturbado do país ${ }^{3}$ - um período muito difícil, inclusive, para os professores desta escola, do ponto de vista político. Ele teve um papel relevante em relação à direção da faculdade ${ }^{4} \mathrm{e}$ a diversos assuntos urgentes e graves; não lhe restava tempo para orientar de maneira corriqueira. Porém, contar com sua visão foi significativo; tenho admiração muito grande por seu trabalho.

que quero dizer é que essa foi a grande alteração ocorrida na USP; por questão institucional da própria Universidade, só quem tinha o título de doutor poderia responder pelas disciplinas. A obtenção do doutorado, circunstancialmente, veio responder também a certo grau de aspiração de minha parte em trabalhar na área de paisagismo. Já trabalhava em projetos de paisagismo desde o final da década de 1950. Por outro lado, - Antunes, que tinha uma didática muito boa - era um comunicador de "mão cheia" na sala de aula - estava cada vez mais se interessando pela pintura; eram muitas as circunstâncias as quais vinham limitando a atividade dele no ensino que fizeram com que tivesse interesse cada vez menor por este. Dizia, então, que tinha dificuldade em compatibilizar "momentos de criação" com os horários de aulas, trabalhos, correções e reuniões. Por mais que se tentasse diminuir, a partir de 1973, os momentos em que se contava com ele, a certa altura, passou a ser importante para ele dedicar-se, integralmente, à pintura, sem cortes, sem interrupções, sem compromissos outros; e ele acabou saindo.

Por outro lado, foi colocada em xeque, por mim, a questão da linha de ensino do Paisagismo que estava sendo dada na escola. Eram outros tempos com relação ao país, à FAU como um todo; o número de alunos foi quintuplicado, a organização da própria escola e as várias seqüências que são os atuais grupos de disciplinas ${ }^{5}$ eram completamente diferentes daqueles conteúdos

(3) Anos 1960-1970 foram de grande conturbação política na Universidade e no país.

(4) Nestor Goulart Reis Filho foi diretor da FAUUSP no período 1972-1976.

(5) Durante o ano de 1962 a FAU passou por completa reformulação didática (Fórum 62), criando-se disciplinas que correspondiam a uma ampliação do campo profissional do arquiteto. Disciplinas afins foram reunidas em departamentos e um deles, o Departamento de Projeto, subdividiu-se em seqüências: Projeto de Edificação, Planejamento Urbano, Desenho Industrial e Comunicação Visual, estendendo o ensino em vários anos letivos. No terceiro ano da seqüência de Planejamento ficaria alocado o ensino de Paisagismo. Durante a década de 1960, a faculdade viria a quintuplicar o número de alunos em relação ao tempo de sua criação; triplicava, no mínimo, o número de professores nas várias seqüências. O Paisagismo se reduzira a um instrutor e a um horário de aulas sob a sigla Planejamento I. 
formulados, em 1952, pelo Roberto Coelho Cardozo e, de certa forma, mantidos em linhas gerais por Antonio Augusto Antunes até $1972^{6}$.

Em meu entender, períodos extremamente cruciais do final da Segunda Guerra Mundial (1939-1945) até a década de 1970, com transformações imensas no mundo todo, na maneira de viver-se, nos comportamentos, na organização, na urbanização e, particularmente, nos processos do Brasil e em São Paulo, já mostravam que não poderia manter o paradigma com o qual se estava trabalhando na década de $50 \mathrm{com}$ a paisagem ${ }^{7}$.

Tive, como docente na faculdade, bastante dificuldade, pois meu processo de amadurecimento foi muito lento e difícil. Achei difícil situar-me em relação às várias correntes da faculdade.

Considero-me brasileira, mas não nasci neste país, mas sim na ltália, e vim para cá com seis anos, quando estava sendo iniciada a Segunda Guerra Mundial. Esse particular fez também com que eu acompanhasse, e percebi isso depois de muito tempo, com mais facilidade ou mais proximidade, ou sentisse mais necessidade de seguir os acontecimentos, as transformações mundiais e o que acontecia em cada lugar. Não creio que as entendesse com muita clareza, mas tenho nítido que é diferente alguém que vive as transformações com o pé mais próximo delas. Claro que não vivi a Segunda Guerra Mundial na Europa; não vivenciei diretamente as transformações da Europa ou dos Estados Unidos. Mas passei por isso de forma muito mais incorporada do que quem acaba lendo nos livros ou tendo um interesse bastante distante. No Brasil, essa preocupação com os acontecimentos nos outros países é relativamente recente. Fico imaginando qual é o significado para as pessoas jovens, que nasceram em meados da década de 80, ler nos livros a respeito desses períodos: a Segunda Guerra Mundial, o Pós-Segunda Guerra, a chegada de (Yuri) Gagarin à Lua e os acontecimentos da União das Repúblicas Socialistas Soviéticas (URSS). Talvez tenham um significado muito distante, em alguns casos, totalmente, desconhecidos; se não desconhecidos, não passam de livros lidos para um exame escolar. $\bigcirc$ (Eric) Hobsbawn, historiador, diz que viveu em tempos interessantes. Acho que vivi um tempo interessante sem os grandes problemas das pessoas as quais estiveram tão próximas a esses acontecimentos. Voltando à questão do ensino de Paisagismo na FAUUSP, o Antunes estava muito só para levar uma turma de 150 alunos com um procedimento de ensino até mais exigente para com a linha que ele dava. Uma linha que exigia uma capacidade técnica de

(6) A Landscape Architecture se desenvolveu como atividade intrinsecamente relacionada ao "design", impregnada da busca contínua de integração do pensamento em arquitetura e paisagem. É importante a contribuição específica do modelo norte-americano, advinda das experiências iniciadas ainda no século 19 por Frederic Olmsted e Calvert Vaux.

(7) A organização do espaço no país, a urbanização, migração e metropolização em São Paulo; vários congressos da União Internacional de Arquitetos (UIA), trabalhos do grupo Economia e Humanismo, cartas de Atenas, de La Tourette, dos Andes, seminários em Nova Delhi e Porto Rico sobre Habitação e Comunidades; em São Paulo, o levantamento de área verdes, o Plano Urbanístico Básico (PUB), o Plano Metropolitano de Desenvolvimento Integrado (PMDI), mostravam a amplitude de temáticas discutidas nas várias seqüências. 
desenho, um acompanhamento mais próximo, quase individual, impossível de fazer sozinho. Os arquitetos que tinham a condução das linhas básicas da FAUUSP, quer antes, quer depois, não tinham o menor interesse com o paisagismo. Então, o que passou a interessar foi o fato de nós introduzirmos novas questões - questões que estavam na vivência do aluno. Eram preocupações dos professores ligados à paisagem, as questões referentes à compreensão do mundo e, muito especialmente da cidade em que se vivia; acredito que esta escola não teve, por muito tempo, o interesse em compreender esta cidade, em colocar sua arquitetura realmente incorporada aos problemas urbanos.

Esse é um problema que sinto até o momento presente; uma dificuldade do arquiteto, do "grande" arquiteto que está por aí, realmente se interessar em fazer com que sua obra tenha alguma coisa a ver com a cidade. Até hoje, se você chama um arquiteto e propõe que ele faça um trabalho sobre o espaço público, ele coloca um objeto sobre esse espaço. É mais uma obra - sua escultura - que ele coloca naquele espaço público, demonstrando, muito freqüentemente, uma despreocupação, um desconhecimento e uma total falta de relação com a cidade.

A manutenção da disciplina de Paisagismo devemos ao Lauro Bastos Birkholz ${ }^{8}$, que considerou que essa área (Paisagismo) não deveria sair da faculdade, porque tinha sido pioneira no Brasil. Acredito que todos esses fatores provavelmente pesaram para que o Lauro, em um momento em que não havia mais a possibilidade institucional de conservar-se a disciplina de Paisagismo com certo grau de autonomia, tomasse para si, dentro da disciplina de Planejamento, o papel de reservar um horário, e era a única coisa que tínhamos, então, para o Paisagismo. Do ponto de vista institucional, ela já havia terminado de vez, e esse foi um dos motivos pelo qual o professor Lauro insistiu muito com o Antunes para que ele fizesse o doutoramento na área. O Antunes teve a intenção de fazer, inclusive com a orientação de pessoas capazes, mas quando chegou no final do prazo, por motivos os mais diversos e que não desmerecem as pessoas, acabou não entregando. Em seu caso, o interesse era maior pela pintura, e isso deve ter pesado muito em relação a um trabalho de doutoramento que, naquela ocasião, tinha de ser feito em um prazo bastante exíguo, sem as mínimas condições bibliográficas.

A biblioteca que vocês conhecem, há 30, 35 anos (anos 1970), não tinha nada a ver com a que temos hoje. Naquela ocasião, a biblioteca tinha menos livros de paisagismo do que eu mesma tinha. Então, se imaginarmos uma pessoa de muitas qualidades, que era o caso do Antunes, com talento e já interessado em outra área, dá para entender por que ele não tinha maiores interesses em aprofundar seus estudos.

Por outro lado, o catedrático na época, Roberto Coelho Cardozo, manteve, do ponto de vista institucional, durante alguns anos com muita relutância, um vínculo com a Universidade de São Paulo; paulatinamente, foi desistin- 
do da titulação e acabou transferindo-se para a Grã-Bretanha. Então, na realidade, na situação histórica em que a Universidade estava organizando quadros institucionais, o fato de não se ter nenhum nível definido para a área de Paisagismo e não se indicando docentes, terminaria-se com ela.

Talvez, a minha única contribuição tenha sido fazer com que, institucionalmente, a área pudesse voltar a existir. Em um segundo momento, coloquei em discussão as bases com as quais se trabalhava, e esforcei-me para tentar montar um arcabouço teórico que não se limitaria àquelas experiências anteriores de aprendizado?.

\section{As Primeiras Experiências}

Foi, para mim, muito interessante depois de formada, ter ainda, em 1956, trabalhado na pesquisa do padre Lebret $^{10}$. Por uma questão circunstancial, consegui trabalhar só na parte de representação gráfica; o responsável não aceitava mulheres trabalhando na pesquisa e muito menos na coleta externa. Esse corte, em certo sentido, até que foi interessante, porque desenhamos as informações todas das coletas de uso e ocupação, equipamentos, circulação, expansão, etc. Tinha comigo uma equipe de jovens estudantes, da arquitetura e da engenharia e participávamos todos da representação. Inclusive, para iniciar o trabalho todo foi preciso atualizar o mapa base da cidade o qual não incluía anos de loteamentos; para mim um período especialmente exigente, mas também instigante. Só muito mais tarde fiquei sabendo que era nossa primeira pesquisa em que, entre os equipamentos públicos essenciais, detectava também os parques e jardins.

fato de ter trabalhado, assim que me formei, na pesquisa do padre Lebret e ter passado, em seu término, para atividades no Departamento de Urbanismo da Prefeitura do Município de São Paulo, foi um choque. Diferentes colegas funcionários do departamento diziam que era para levar o próprio trabalho e receber o salário; logo pedi demissão. Mas essa chance de ter trabalhado na pesquisa do padre Lebret, que funcionava de uma forma completamente diferente, com muita dedicação e envolvimento; mais tarde, ter defendido nossas atividades e posicionamentos em um grupo de disciplinas de Planeja-

(8) Lauro Bastos Birkholz entrou como assistente de Luís de Anhaia Mello na disciplina Urbanismo, em 1957; tornou-se catedrático de Planejamento II por concurso, em 1967. As origens desse campo disciplinar na FAU eram fortemente influenciadas pelo ensino na Grã-Bretanha; incluía a questão do paisagismo como sistema de espaços abertos, praças e parques.

(9) As dificuldades para se dedicar à reflexão acabariam por valorizar fortemente a transferência do processo de projeto do escritório, sem a possibilidade de maior preocupação crítica.

(10) A pesquisa ficou sendo conhecida pelo nome do padre Lebret, chefe da equipe contratada pela prefeitura municipal de São Paulo, em 1956 - uma pesquisa socioeconômica na aglomeração paulistana realizada pela Sociedade para a Análise Gráfica e Mecanográfica Aplicadas aos Complexos Sociais (SAGMACS) e a Comissão de Pesquisa Urbana da Prefeitura Municipal de São Paulo, formada por uma equipe de urbanistas e funcionários municipais. 
mento em que se tinha profissionais de posições ideológicas e teóricas muito díspares - como sempre foi o grupo de Planejamento - e ao mesmo tempo, ter sido estagiária nos escritórios de arquitetura do Abelardo de Souza, de paisagismo do Roberto Coelho Cardozo por muitos anos, um pouco de estágio com Eduardo Corona, alguns meses em desenhos de mobiliário de Joaquim Tenreiro e ter feito com Nestor desenhos para o Luís Saia na apresentação do IV Centenário mostraram-me, que, realmente, o Departamento de Urbanismo de então não era o que eu queria para minha vida.

Nestor Goulart Reis Filho e eu desenhamos ${ }^{11}$ todos aqueles trabalhos que o Luís Saia apresentou no IV Centenário de São Paulo, o que foi muito rico para ambos. Nestor, um dia desses, comentou que foi um dos temas que o levou para a pesquisa histórica que acabou desenvolvendo. Éramos estudantes ainda nessa época. A exposição do Saia referia-se ao conhecimento que se tinha a respeito dos trabalhos do Serviço do Patrimônio ${ }^{12}$. Esse serviço ainda não existia com a organização que conhecemos hoje. E o Saia foi uma das pessoas com a maior contribuição para o conhecimento da morada paulista. Naquela época, Saia fez o mais completo levantamento, do ponto de vista histórico, que se tinha em relação ao processo de urbanização da cidade e aos sítios históricos.

Esse levantamento acabou fundamentando o trabalho do Conselho de Defesa do Patrimônio Histórico, Arqueológico, Artístico e Turístico do Estado de São Paulo (Condephaat), do Conselho Municipal de Preservação do Patrimônio Histórico, Cultural e Ambiental da Cidade de São Paulo (CONPRESP). Tudo isso era completamente novo quando o Saia apresentou, em 1954, sua exposição no lbirapuera, por ocasião da comemoração do IV Centenário.

Para mim, essa exposição teve menos peso do que para o Nestor. $\bigcirc$ que pesou, de fato, foi essa oportunidade de estar em campos diferentes procurando, como profissional muito jovem e recém-formada, aprender em diversas áreas sem ter ainda qualquer decisão de condução profissional para um determinado campo.

Não tenho dúvida que os meus primeiros trabalhos tiveram uma influência fortíssima do Roberto Coelho Cardozo. Trabalhei por muitos anos como aluna e depois, como recém-formada; nunca dei aula com ele; porém, tivemos um trabalho bastante intenso, de modo que era muito fácil ser influenciada por seu desenho - um desenho que respondia ao que era considerado arquitetura moderna. Também sou cria da arquitetura moderna. Ainda não derrubei os princípios da arquitetura moderna, a arquitetura da Bauhaus. Procurei entendê-la em seu tempo e espaço ${ }^{13}$. Outro aspecto que teve um peso mais forte, no que concerne ao processo de projeto, foi o conhecimento maior dos movimentos em relação aos espaços públicos. $\bigcirc$ estágio com o Roberto Coelho Cardozo teve muita importância, mas não diria que de forma mais expressiva do que com o Abelardo de Souza. 
Abelardo de Souza, carioca, que se mudou para São Paulo ainda na década de 1940, foi um dos arquitetos da geração pioneira da arquitetura moderna brasileira. Tem alguns trabalhos muito interessantes; talvez seja um dos poucos professores que nunca teve uma exposição de seus trabalhos patrocinada por esta faculdade. Ele pertenceu ao Partido Comunista, mas não tinha uma liderança retórica. Tinha um trabalho de base, de organização financeira. E, quando passou a ter algumas restrições a ações da URSS, na Hungria, na Tchecoslováquia, etc. - restrições muito resguardadas, foram fortemente prejudiciais em sua carreira profissional, quer como professor quer como arquiteto. Este é, muito provavelmente, um dos motivos básicos pelos quais ninguém até hoje fez uma exposição de seu trabalho. Foi muito importante ter estado em seu escritório, onde sempre teve colegas nossos como estagiários; arquitetos e professores reconhecidos que o próprio Abelardo introduziu no ensino e na profissão - por exemplo, o (Jon Andoni Vergareche) Maitrejean, o próprio (Jorge) Caron, falecido há dois anos (2002). Diria que outro aspecto positivo era a abertura que ele tinha em relação à participação das artes e das demais áreas, em geral, na arquitetura. Era um ser humano impressionantemente bom, generoso, que dificilmente estaria lidando com as questões do ensino e da profissão com uma visão personalista. Tinha uma visão realmente de afeto e de construção para com os demais. É até difícil avaliar se a arquitetura do edifício parecia-me tão importante pelo prazer dela, em si, ou pelo fato de encontrar uma pessoa com essas características, raras já naquela ocasião, inclusive dentro desta faculdade.

Em meados de 1958, houve o "Primeiro Concurso Nacional de Praças", promovido pelo Rio Grande do Sul, na cidade de Cachoeira do Sul. Era uma praça bem interessante e ampla, a praça principal da cidade, e tive a sorte de tirar o primeiro lugar. Vendo, depois de alguns anos, aquela primeira proposta que tinha feito, diria que era bastante primária, porém não era difícil perceber que era inovadora em relação aos desenhos que se faziam na ocasião, no país, e esse trabalho gerou um contrato para seu desenvolvimento. $O$ projeto foi detalhado, mas a praça nunca foi executada. $\mathrm{Na}$ época, estava até morando em Porto Alegre. $\mathrm{O}$ julgamento foi feito por arquitetos de altíssimo nível, deixando-me muito lisonjeada. Recordo pelo menos do Carlos Maximiliano Fayet e do Demétrio Ribeiro ${ }^{14}$, considerado o melhor urbanista do Rio Grande do Sul. Eles propuseram, inclusive, que

(11) Houve também a participação do colega arquiteto Wladimir Kliass, falecido na década de 1980.

(12) SPHAN - Serviço do Patrimônio Histórico e Artístico Nacional (conhecido como "o Patrimônio").

(13) Reflexão maior a respeito da concepção de arquitetura e a incorporação do "design" no paisagismo ainda merece outras elaborações.

(14) Demétrio Ribeiro foi uma das figuras mais significativas do pensamento sobre a arquitetura no Brasil; atuando em Porto Alegre, desde final da década de 1940 até poucos anos atrás, como professor e profissional, contribuiu sensivelmente para a formação e discussão das questões sociais e suas implicações nas atividades profissionais. 
se abrisse a disciplina de Paisagismo na Faculdade de Arquitetura de Porto Alegre e, em face do resultado do concurso, ofereceram-me a disciplina. Mas me encontrava inteiramente despreparada para isso e recusei. Fiquei sete meses em Porto Alegre, voltando para lá somente para complementar o desenvolvimento desse projeto da praça.

Com Rosa (Grena) Kliass comecei em 1958-60 a fazer alguns trabalhos de paisagismo. Fomos sócias durante alguns anos e era um trabalho extremamente limitado, porque o campo de atuação existente pouco ultrapassava os espaços mínimos e recuos das habitações dentro dos lotes. Essa atividade se restringia ainda a algumas habitações mais excepcionais, projetos de arquitetos mais conhecidos, em que o cliente realmente queria um trabalho mais completo.

Continuo julgando aquilo um adorno, uma moldura à arquitetura do edifício que estava sendo feito. Espaços extremamente exíguos, aqueles recuos laterais de dois metros e aqueles recuos de frente e de fundos. Esse trabalho era muito similar ao que o Cardozo também fez em algumas ocasiões, onde teve um ou outro trabalho com lotes um pouco maiores. Rosa e eu fizemos dois ou três projetos para edifícios de apartamentos, tendo sido, no geral, projetos para residências, e fizemos uma praça em São Roque que não foi executada. Na volta a São Paulo, Rosinha e eu intensificamos os trabalhos e acabamos desenvolvendo um número razoável de projetos, além do Ocian Praia Clube e alguns jardins de edifícios. Continuamos com a sociedade por mais alguns anos e depois voltei a trabalhar com o arquiteto Abelardo de Souza, desenvolvendo projetos de arquitetura de edifício.

Os primeiros projetos foram muito mais uma introdução a diferentes programas disciplinares e, também, uma procura de linguagem própria. Foi muito fácil para nós adotarmos uma linguagem similar à do Roberto Coelho Cardozo, (Garrett) Eckbo, (Robert) Royston, toda a linha "californiana" do que uma linguagem "Roberto Burle Marx" - dois Robertos que foram, na montagem da faculdade, de pesos completamente diferentes um do outro. Esses 20 anos foram tentativas de procura de abertura do mercado. Creio que se conseguiu fazer isso realmente e a prova está no próprio trabalho profissional, insatisfatório sob vários aspectos, mas que está aí, e que não existia há 30, 40 anos.

Houve uma abertura do mercado, a oportunidade de mostrar o trabalho de paisagismo em diferentes programas, desde projetos de áreas residenciais unifamiliares e plurifamiliares, até clubes, praças, parques e planejamento urbano. Talvez, no planejamento urbano, teria sido melhor obter maior participação do arquiteto trabalhando com a paisagem. Vejo necessidade de trabalhar-se as questões sobre meio ambiente, mas realmente não é ainda consistente o que fazer na prática. Creio que já seria bastante: abrir mer- 
cado e linhas de programa. Na prática profissional, em planos e projetos, os processos de reflexão que a faculdade me deu ajudaram-me a lidar com colegas de outras áreas, insistindo para um cuidado maior em relação à interdisciplinaridade, à cidade e com o que é público.

\section{O Trabalho com a Prefeitura de São Paulo}

Em 1967, Rosinha e eu já não éramos sócias, mas fizemos juntas o primeiro levantamento de espaços livres destinados a praças para a Prefeitura do Município de São Paulo. Estou fazendo questão desse título, porque há um entendimento que o mesmo era um plano de áreas verdes de recreação; em uma das exposições do Instituto de Arquitetos do Brasil (IAB) o trabalho recebeu o nome de uma das pranchas que fizemos, chamada "Áreas verdes de recreação".

Além de não estarmos contratadas para fazer um plano, é preciso ter claro que a constatação do existente não se constituía em um plano. Estávamos sendo contratadas para levantar as propriedades que a prefeitura tinha em seu patrimônio, destinadas a praças e parques. Naquela época, em 1967, a prefeitura não sabia o que tinha em seu patrimônio. Foi penoso conseguir levantar, registrar e cadastrar todos os espaços livres pertencentes ao município, pois na maior parte das vezes o conhecimento era da memória de algum funcionário antigo da prefeitura. Algumas áreas foram literalmente encontradas por meio de conversas de nossos topógrafos com a população local. Nós nos propusemos a estudar qual a demanda da população que essas áreas, pertencentes à prefeitura, poderiam atender.

Outra parte do contrato envolvia a realização dos projetos para vinte e poucas praças, escolhidas fundamentalmente, pelo prefeito e vereadores, a esmo, sob o aspecto dos interesses da cidade; na realidade, "tratar" essas praças é que interessava ao prefeito.

Outro item dizia respeito ao levantamento da situação dos viveiros da prefeitura municipal. Esse trabalho foi realizado com um conhecido botânico da época, Harry Blossfeld; um trabalho extremamente interessante, no sentido do levantamento das condições e com uma proposta de novos plantios, que deveriam ser feitos nos viveiros para aperfeiçoar as plantações. Não havia a menor preocupação com as árvores brasileiras, e Blossfeld estava muito mais relacionado com as árvores exóticas, as quais estavam sendo plantadas nos jardins particulares. Então, caberia uma revisão muito séria no aspecto das propostas das novas mudas que seriam feitas, e não no aspecto de propostas em relação ao que deveria ser um viveiro da prefeitura. A prefeitura mantinha, para fazer a manutenção das ruas e praças da cidade, viveiros. É falha grave de nossa parte a falta de reflexão ponderada e aprofundada sobre a questão, bem mais séria, das plantas nativas. 
Sobre os projetos da década de 1960, nós - Rosinha, (Maria) Maddalena Ré, Edith (Gonçalves de Oliveira) e eu - levamos o que era considerado, na época, algo relativamente inovador para os espaços de recreação: a questão do esporte e do movimento, etc. Acabamos mantendo o que se estava fazendo na Europa e nos Estados Unidos, procurando um questionamento mais forte no Brasil, sobretudo em São Paulo, do papel e dos programas das áreas livres públicas para recreação e lazer.

programa adotado era definidor do partido que se assumia. Este se baseava em uma pesquisa realizada por um grupo de sociólogos, de excelente nível, coordenado pela Eugênia Paesani e seus colegas ${ }^{15}$ sobre uma área que era considerada de maior interesse por uma população de classe média - o Centro Educacional da Mooca. Foi feito um levantamento sobre qual era o maior interesse dessas populações e como essas populações faziam uso, em que ocasiões e quais eram as demandas.

Hoje em dia, poder-se-ia considerar isso como uma forma de participação - que naquela época não existia - uma forma de participação social que teria sido inovadora para um processo de projeto. Essas demandas e sua argumentação sociológica foram uma base extremamente importante para dar a diretriz fundamental para esses espaços.

Passados alguns anos, fui procurar muitas das tais áreas e não as encontrei. Acabei descobrindo que elas estavam na Secretaria de Esportes; as poucas áreas maiores nas quais foi possível fazer uma distribuição de equipamentos de maior porte converteram-se nos tais Centros Educacionais e Esportivos da Prefeitura Municipal. Falha, que aí já não foi nossa, foi o fato que havíamos realizado projetos reduzidos ao mínimo possível, para que os recursos durante a execução fossem menores, permitindo um maior número de espaços ocupados. Houve três cortes violentos nessa execução - cortes estes que invalidavam a proposta completamente - sendo que os dois últimos, Rosa e eu chegamos a documentar. Queríamos que o trabalho viesse a ser incorporado pelo Plano Urbanístico Básico (PUB) e fizemos vários contatos para isso, não obtendo resultados satisfatórios.

Uma consideração importante é que o fato de terem sido levantadas essas áreas, ainda que algumas muito mal equipadas, fez com que a grande maioria delas se mantivessem conservadas, não sendo perdidas para usos particulares ou públicos, como até então vinha ocorrendo sistematicamente. Utilizava-se o espaço destinado à praça de muitas maneiras: para um empreendedor fazer seu edifício, sua loja ou o que fosse, para colocar um posto de saúde, uma

(15) $\bigcirc$ Comércio de Materiais de Construção Ltda (Cemaco), empresa que reunia sociólogos e arquitetos, realizou pesquisa para detectar o que seria representativo em termos de recreação. 
escola - equipamentos esses indispensáveis, dos quais a população precisa, da mesma maneira que áreas de praças.

A naturalidade com a qual se abre mão do espaço livre público, destinado para tantos outros fins, é um problema que encontramos até hoje na prefeitura, na própria Secretaria Municipal do Meio Ambiente e em várias outras secretarias. Andei discutindo isso há algumas semanas na Secretaria Municipal do Meio Ambiente, na condição de representante do Instituto dos Arquitetos. É normal que se ouça: "Existe uma praça e nós vamos colocar um terminal de ônibus", como o terminal de ônibus de Parelheiros. $\bigcirc$ terminal de ônibus de Rio Bonito só não está em cima da praça, porque nela foram implantados equipamentos. No dia em que a Secretaria Municipal levou-nos para ver a área em que está sendo implantado o eixo Corredor Rio Bonito, a Secretaria de Transportes disse, em relação à área a ser implantado o terminal de ônibus: "Aqui não deu, porque está sendo usado". Havia centenas de crianças utilizando aquelas áreas, crianças da redondeza que estavam "atrapalhando a implantação do terminal de ônibus".

Dizer que foi uma vantagem para a cidade ter conseguido "segurar" essas áreas é muito pouco, mas foi importante, porque nem essas áreas nós teríamos hoje.

Desde 1967 acabei firmando, em definitivo, minha opção pela área de paisagismo e, depois, só muito raramente, dediquei-me a outras atividades. Quando comecei a dar aula de paisagismo, em 1973, tinha não só trabalhos realizados com a Rosa, mas também trabalhos meus. Esse levantamento foi um trabalho significativo no sentido de fazer-se um reconhecimento mais cuidadoso com a cidade de São Paulo e seus espaços livres. Tivemos, ainda, a contribuição da Edith Gonçalves de Oliveira, da Maria Maddalena Ré, as quais, na ocasião, recentemente formadas, tiveram uma participação muito ativa. Júlio Katinsky, Abrahão Sanovicz e (Bramante) Buffoni, um artista plástico, por seu lado, desenvolveram para o Instituto de Pesquisa e Ação Social (IPAS), por um contrato que fizemos com eles, equipamentos públicos para as praças. Os equipamentos a que estou me referindo eram: bancas para jornais, bancos, luminárias, postes. Nossa idéia era criar uma solução de design seriado que pudesse vir a ser feito com um bom nível de desenho e de artefato, de modo a responder não somente àquelas vinte e poucas praças que tínhamos como projeto, mas que a cidade passasse a ter praças equipadas. Para isso seria levantado o local, prevista qual a área que aquela localização poderia atender enquanto demanda de vizinhança, implantados os viveiros de modo a terem mudas permanentemente e planejados os equipamentos. Isso tudo, em nosso entender, poderia ter dado uma redução dos custos e uma maior possibilidade na execução dos projetos, dando margem a que se organizasse o Departamento de Parques e Áreas Verdes (Depave) da cidade. Trabalhamos no galpão do (Viveiro) Manequinho Lopes, e alguns arquitetos foram, como 
outros tantos profissionais de outras áreas, como biólogos, agrônomos, etc., sendo contratados para fazer parte do Depave por meio de nosso contrato. Participariam de nosso trabalho e assumiriam, dentro dessa participação, até o papel de aprová-lo, dando certa consistência a esse novo departamento que se estava criando e passariam, depois, a assumir os projetos de todas as praças da cidade. A Ayako (Nishikawa) era uma das pessoas, como a Eleonora (Seligmann), e a Vera Ilse (Monteiro da Cruz).

A participação conjunta de linhas profissionais interdisciplinares: arquitetura, biologia, engenharia agronômica, engenharia florestal poderia ter sido muito benéfica para a cidade, mas acabou praticamente mudando de mãos. $\bigcirc$ Depave é, hoje, fundamentalmente, local de trabalho de engenheiro agrônomo ou florestal e alguns biólogos, que não têm formação para o trabalho de projeto. Têm preparo para outros aspectos importantes na secretaria. Seria muito interessante se houvesse real apoio e integração entre as diferentes formações levando a contribuições de pesos diferentes, conforme os aspectos em questão. Mas, na realidade, acredito que nunca tivemos a capacidade, ambos os lados, de conseguir levar adiante um trabalho mais rico nessa interdisciplinaridade - o que prejudica muito a área de trabalho.

\section{A Construção da Área de Paisagismo na FAUUSP}

Grupo de Disciplinas de Paisagem e Ambiente (GDPA) acabou surgindo, depois de muito tempo, dentro do Departamento de Projeto (1988). É importante a ênfase em trabalhar em uma atividade profissional que inclua a prática de planos de projeto com a prática didática de ensino e pesquisa. Naquela ocasião, em 1973, não conseguimos profissionais da área para atuar como professor da disciplina. A disciplina de Paisagismo, por não existir institucionalmente, não tinha recursos disponíveis. Na década de 1970, os recursos para a Universidade eram muito menores que em décadas anteriores. Muito menos importante para a faculdade era o fato de conseguir-se professores para o Paisagismo, pois era uma área para a qual não se dava a menor importância na formação profissional do arquiteto.

Em 1968, fiz um curso na Inglaterra e na Dinamarca, curto e intensivo, sobre "Town and Country Planning". Em 1970, participei do Plano Metropolitano de Desenvolvimento Integrado (PMDI), tendo, então, já elaborado quase uma centena de projetos no escritório de diferentes tipos. Ficar, portanto, com aquele plano de trabalho da disciplina, que tinha sido montado em 1952-55, e que, no fundo, era uma versão do curso de "Landscape Architecture", da Califórnia, adaptada às situações de tempo (e eu nem diria situações culturais e históricas do país, mas adaptada a situações de tempo da disciplina - horas-aula disponíveis) era insatisfatório. Era indispensável, para mim, fazer a reavaliação e atualização. 
Mudamos a disciplina para o primeiro ano, porque sentíamos que os alunos já vinham "viciados"16. Outro aspecto que pesou muito foi a vitalidade da equipe. Havia instrutores - nome que se dava aos professores no nível inicial - com muita vontade, dispostos a reuniões, e discussões, muito envolvidos e dedicados ao trabalho. Isso acabou levando a um processo de participação maior dos alunos, que foi sendo obtido conforme conseguíamos avançar ${ }^{17}$. Primeiro, com uma participação forte junto dos alunos, uma participação que abrangia desde uma preocupação com a escolha do tema, os motivos, a visão de mundo que estava por trás, as possibilidades de elaboração daquilo e uma preocupação com o trabalho das equipes e de cada um dentro das equipes.

Foram 12 anos de reunião e muito trabalho. Era importante que os procedimentos didático-pedagógicos fossem a base de razoável identidade coletiva da equipe, sendo indispensável criar nossa massa crítica, com a obrigatoriedade de esses instrutores fazerem a pós-graduação. Montávamos as disciplinas de pós-graduação, porque sentíamos que era importante, porém, sabíamos que não tínhamos matéria suficiente para elas. Na verdade, a pós-graduação tinha um papel extremamente importante, no sentido de conseguir discutir essas questões e montar um arcabouço teórico. Os projetos de pesquisa acabavam respondendo a uma inquietude daqueles que os desenvolviam e eram debatidos em aulas com os alunos.

Revejo, hoje (2003), vários daqueles textos e conceitos sintetizados em 1979 80. Deveria dizer que alguns até me satisfazem, embora redigidos, freqüentemente, de forma muito hermética. Um capítulo o qual deveria ser totalmente refeito é aquele sobre o conceito de paisagem, que sempre foi e é, para nós, um conceito muito complexo. Volta e meia penso que talvez estivesse em condições de escrever alguma coisa um pouquinho mais clara e atualizada. Porém, pessoalmente, foi um avanço muito grande e acredito que deixaram algumas marcas para vários colegas e algumas colocações da disciplina, em uma tentativa de compreender a questão da paisagem, mais especificamente sobre espaços livres. A paisagem, nesses conceitos, aparece mais como uma forma muito rudimentar, quando aparece. Em relação à Grande São Paulo, diria que talvez, do ponto de vista da paisagem, melhor do que o que está escrito no documento de minha livre-docência é um texto do Plano Metropo-

(16) O aluno já vinha preparado em dois anos pelo professor de Projeto de Edificação para "colocar o molho", aliás expressão típica dos escritórios de arquitetura; era muito difícil levá-lo a lidar com a edificação e seu entorno, e a implantação no lote; com a dicotomia edifício-cidade; a percepção do espaço livre de edificação; o significado das localizações na cidade, etc.

(17) Com muitas dificuldades fomos, paulatinamente, inserindo novas disciplinas, apesar de problemas de horários na grade, de vagas para docentes, de vagas para nossos candidatos na pós-graduação, de sala para trabalho. Era preciso tudo disputar: espaço, tempo, recursos, bolsas; não passávamos de uma pequena área dentro do Grupo de Disciplinas de Planejamento, dentro do Departamento de Projeto. 
litano de Desenvolvimento Integrado (PMDI) chamado Aspectos paisagísticos, o qual desenvolvi com o Waldemar Cordeiro, que considero desatualizado, mas para a época (1971) era muito bom. Esse texto serviu para nos ajudar a montar uma metodologia de análise dos aspectos paisagísticos. No texto Espaços livres e metropolização, trabalhamos muito mais diretamente com os espaços livres e menos com o conceito de paisagem ${ }^{18}$.

Escrevo e identifico algumas coisas que não publico. É importante passar para os orientandos que refletem sobre as questões e escrevem bem melhor do que eu.

Durante 10, 11 anos de tempo integral na faculdade, senti-me amputada da prática de planos e projetos. Essa volta à prática dos planos e projetos (1990) trouxe muitos aspectos interessantes e altamente frustrantes, sobretudo, o fato de quão pouco nos é cobrado fora. Nos últimos 10 anos, quis fazer com que os trabalhos profissionais conseguissem incorporar parte da reflexão, da discussão e do juízo crítico que a faculdade realmente ajudou-me a ter. Pude observar que o que se consegue colocar na prática profissional é uma contribuição bastante reduzida do que é, de fato, possível em relação ao espírito de investigação que a faculdade consegue dar. As barreiras são terríveis, pelos mais diversos aspectos. Para o cliente é mais lucrativo fazer uso de um profissional que não lhe imponha questões; um que the responda com as ferramentas disponíveis para que aquele trabalho tenha um bom marketing e uma boa venda.

\section{A Formação da Equipe}

Até 1976, o que tivemos foi o apoio de alunos os quais se tornaram monitores depois de formados. Eu lembraria dois apoios fundamentais, Silvio (Soares Macedo) e Sun Alex. Dois monitores básicos que tivemos para levar a disciplina adiante. Entre o final de 1975 e 1976, conseguimos obter, com a aprovação da direção do Nestor, a chance de algumas vagas para professores. O professor Nestor e eu convidamos duas pessoas que já trabalhavam na área e eram razoavelmente conhecidas - Rosa Kliass e Fernando (MagaIhães) Chacel -, visto que o campo de trabalho era diminuto. Os dois tiveram algum interesse, desde que sua participação pudesse ser em regime parcial, o que significava 12 horas-trabalho por semana, sendo seis de aula e seis de reuniões, preparos, correções, e desde que esses horários pudessem ter certa fluidez, porque eles não poderiam deixar suas atividades de escritório dependentes dos horários da faculdade.

22 Eu tinha bastante claro, com apoio do próprio departamento e da diretoria, que só se poderia criar uma massa crítica se a Universidade contasse com professores obrigados a desenvolver pesquisas e a assumir a pós-graduação como uma de suas tarefas a enfrentar em curto prazo. Isto significava, no 
mínimo, um regime de turno completo ${ }^{19}-24$ horas semanais. Então, foi uma condição sine qua non para que as pessoas as quais se apresentassem a esse concurso devessem assinar um documento, concordando com um regime que Ihes exigiria participar da pesquisa e da pós-graduação. No fundo, esse é o motivo pelo qual nunca estiveram Rosa Kliass e Chacel dando aulas nesta faculdade, somente em uma ou outra palestra. É uma questão de pesos a dar-se aos próprios escritórios e à Universidade. Julgávamos que, desde que houvesse interesse, a compatibilização seria possível e necessária, no entanto, somente se interessaram algumas pessoas mais jovens, recém-formadas e que não tinham, porque não era possível se ter, uma prática de projeto naquela ocasião. Aliás, Ayako (Nishikawa) e Eleonora (Seligmann) até tinham e eram muito competentes. Então, entraram como professores o Silvio, o Sun Alex, a Maria Angela (Faggin Pereira Leite), a Ayako e a Eleonora. $\bigcirc$ Benê (Benedito Abbud) entrou mais tarde, na vaga da Eleonora; depois ele saiu devido ao incremento de trabalho de seu escritório, conseguindo, ainda, realizar seu mestrado na faculdade.

Não conseguimos continuar com todos - o que teria sido muito bom no sentido da estabilidade, da progressão dos trabalhos. Houve várias mudanças naquela equipe. Hoje, daquela equipe temos só o Silvio e a Maria Angela. Entraram vários outros com contribuições muito ricas: os professores Maria Assunção Ribeiro Franco, Vladimir Bartalini, Catharina (Pinheiro Cordeiro dos Santos) Lima, Paulo (Renato Mesquita) Pellegrino, Klara Kaiser Mori, Fábio Mariz Gonçalves, Euler Sandeville Júnior, Eugenio (Fernandes) Queiroga. Entendo que temos uma equipe de professores com uma pluralidade de interesses e de competências muito grande. Em 1976, com uma equipe muito menor e menos preparada, fizemos um esforço muito grande, com discussões intensíssimas e com tremendas dúvidas para encontrar um novo caminho. Acho que foi uma tentativa de construir um processo de trabalho que continuou, pelo menos até 1990. Cito essa data, pois está ligada ao período em que me aposentei e deixei de participar do curso de graduação.

\section{Paisagem e Meio Ambiente}

As muitas pesquisas elaboradas para os mestrados e doutorados apoiaram a ampliação dos espaços na graduação e uma razoável difusão do ensino pelo país. $\bigcirc$ grupo se propôs, na década de 1990, a organizar um evento

(18) Ambos os textos tiveram revisão da redação final da arquiteta Dora $\mathrm{H}$. de Londoño.

(19) Desde início de 1970 havia-se criado na USP o Regime de Turno Completo, além do Parcial (12 horas) e do Integral (40 horas). A maioria dos arquitetos havia optado por esse regime que reserva horas para pesquisa; ao ser aluno da pós-graduação, necessária para a renovação dos contratos, fazia-se uso de parte dessas horas. Durante muitos anos os prazos de conclusão dos mestrados conseguiram ser muito dilatados; o professor mantinha vínculos contratuais provisórios com a Universidade. 
que reunia as áreas de paisagismo das escolas de arquitetura do país, e viesse a divulgar e debater as experiências, métodos, propostas de ensino e pesquisa. A esse primeiro colóquio, realizado na FAUUSP, em dezembro de 1993, seguiu-se o I Encontro Nacional de Ensino de Paisagismo em Escolas de Arquitetura (ENEPEA), realizado no Rio de Janeiro, em 1994; em julho de 2005 chegava-se ao VII ENEPEA, sediado em Belo Horizonte.

Nestor, responsável por nossa primeira abordagem sistemática da urbanização como processo social, já havia mostrado que ainda no "patrimônio" os edifícios a preservar tinham de relacionar-se com suas "áreas envoltórias"; era a relação entre o arquitetônico e o urbanístico. Especialmente levando em conta as contribuições e as modificações nas duas últimas décadas, a política do meio ambiente, a participação da própria população no que se refere à questão ambiental e às transformações do ponto de vista do papel que esta palavra "ambiente" vem assumindo, inclusive do ponto de vista de política internacional, por parte de nós, arquitetos, os quais trabalhamos com a paisagem e o ambiente, ficam aspectos que ainda precisam de maior dedicação.

No período de 1976 a 1989, "paisagem" e "ambiente" eram conceitos extremamente vinculados aos processos de urbanização. E esse é o lado que sinto que precisa de uma dedicação, no sentido de identificar os aspectos de contribuição, questionar uma visão já solidificada em diferentes enfoques e abordagens - a cidade é vista por meio de fragmentos: zoneamento, transporte e circulação, habitação, habitação para pobres. Por exemplo, uma proposta da Secretaria Municipal de Habitação (Sehab) em que "se faz a concessão" de deixar os excluídos nos lugares que invadiram, devidamente caracterizados em seu espaço, bem segregados. Os planos regionais não propuseram nada no sentido do uso misto - o que está no último Plano Diretor Estratégico do Município de São Paulo. A própria Sehab propôs o uso de quadras inteiras por grupos sociais, sempre dentro da mesma classe. Essa igualdade da diferenciação precisa de um trabalho interdisciplinar, pelo menos dentro da arquitetura. Sou favorável a que se abra essa interdisciplinaridade para outras áreas, mas nós sequer conseguimos isso dentre os arquitetos.

Foi muito válido ter trazido o professor Milton Santos para esta escola, ministrando disciplinas de pós-graduação e palestras no final dos anos de 1970. Nesses tempos houve uma intensa troca de reflexões e experiências entre os professores, possibilitando a criação de uma base de trabalho, no âmbito do paisagismo, bastante consistente e o qual tem servido também para outros núcleos de ensino no Brasil. Milton Santos era uma pessoa excepcional e sua participação na Faculdade de Arquitetura e Urbanismo foi extremamente proveitosa para nós e muito rica para ele. Ainda é importante para mim, entre tantos outros aspectos marcantes, recordar que, quando ele falava sobre espaço, referia-se ao espaço geográfico; chamava-nos a 
atenção que um conceito, elaborado em uma disciplina ou em uma área do saber, raramente é um conceito também para outra área do saber. Colocava que, na maioria das vezes, os conceitos elaborados em uma disciplina são metáforas para as outras; explicava ainda que a apropriação de um conceito, de uma elaboração, busca dar conta da estrutura da realidade vista por um especialista; e este vê apenas um aspecto da realidade. Alertavanos para os equívocos vindos de apropriações sem reelaboração; dizia que era necessário fazer a apropriação como uma tradução, ao mesmo tempo generosa e rigorosa.

\section{Posturas}

Devo minhas posturas éticas a meu pai e a minha mãe. Creio que me incutiram o significado da coerência entre ações e convicções que procurei não deixar de lado. $\bigcirc$ que mudou, com o tempo, foi a capacidade em identificar melhor, em cada projeto, o que poderia ser o cerne da contribuição que se pode dar. Exemplificando, um dos projetos mais significativos do começo da minha volta ao escritório foi, no início da década de 1990, o late Clube de Angra dos Reis. $\bigcirc$ que poderia ter sido um projeto de uma grande área, acabou virando uma necessidade de transferir, ao cliente e à Secretaria do Meio Ambiente da região, o respeito pela paisagem. Aquele local, ao lado da praia do Frade, era ocupado em grande parte por enormes blocos de pedra, típicos daquela paisagem extremamente rica, como é toda Angra. Os blocos de pedra estavam sendo cortados pelo arquiteto do edifício, com autorização do Conselho do late Clube, composto por pessoas que tinham comprado, no projeto, seu chalé e a área virtual, dos quais faziam parte alguns dos nomes mais conhecidos de nossa arquitetura e de nossa engenharia. Aliás, fui convidada por alguns arquitetos proprietários para colocar alguns canteirinhos simpáticos e coloridos na frente de suas janelas. Assumi aquele trabalho de reconstituição da mata do morro, que estava inteiramente pelado, erodido com voçorocas terríveis, e sobretudo, que aquelas pedras não iriam mais ser material de construção dos chalés. Por pouco não fui excluída do projeto - que me interessava muito sob vários aspectos. Além disso, não foi fácil convencer a Secretaria do Meio Ambiente de que lhe cabia exigir dos proprietários preservar e proteger aquela paisagem que possuíam.

Ter uma curiosidade intelectual e fazer questão de um juízo crítico é fundamental para ambos os lados. $\bigcirc$ papel da Universidade é induzir e estimular o juízo crítico. Assumir o papel de propor, de intervir, distanciando-se da compreensão dos fenômenos limita muito o indivíduo e sua contribuição. Estou colocando em discussão uma coisa que estou cansada de ouvir: ensinar ao aluno-arquiteto a ferramenta do escritório para que ele possa ser considerado um profissional adequado. Por outro lado, tenho tido a oportunidade, com muita freqüência, de observar que, quando você tem um estudante ou um recém- 
formado ao qual tenha sido incutido ou aperfeiçoado esse sentido crítico, a ferramenta do escritório se libera com muita facilidade. Com alguns meses de prática, ele domina essa ferramenta, porém, não fica dono de um processo investigativo e de um processo de reflexão, se ele não tiver sido estimulado antes. A reflexão e a preocupação de identificar os aspectos com os quais se pode contribuir eram muito mais difíceis. $\bigcirc$ escritório não pode proporcionar isso. Lembro-me, inclusive, de uma frase do livro Entornos vitales - hacia un diseño urbano y arquitectónico más humano - manual práctico - "A forma seria o resultado de atitudes políticas e sociais progressistas", atitude que se encontra profundamente arraigada na tradição da arquitetura moderna - em que os autores mostram como o fato de as pessoas possuírem uma ideologia consistente não faz com que suas idéias projetuais, automaticamente, consigam ser rebatidas. $\bigcirc$ que eles procuram mostrar é que não basta ter clareza e uma maior vontade de igualdade social, de melhores condições de vida para que seus projetos tenham isso incorporado; é preciso encontrar as implicações formais desses ideais. Todos nós precisamos de um preparo geral sério, intenso, bem feito, de História, Geografia, Filosofia, Sociologia e Antropologia, para que sejamos pessoas abertas, sérias, mais completas. Mas nosso trabalho vai ter de sair como contribuição do arquiteto, porque, senão, seria como se o saber arquitetônico não tivesse valor e como se não conseguisse perceber o quanto é importante para as pessoas, dentro dos aspectos fundamentais (como saneamento, água, etc.), também ser fundamental viver em um ambiente construído que lhes seja bom, confortável, livre, enriquecedor e belo. 